\title{
Emergência e crescimento inicial de plântulas de Eugenia jambolana Lam. após remoção da polpa
}

\author{
Emergence and early growth of seedlings of Eugenia jambolana Lam. after removal of the pulp
}

\author{
Luciana Rodrigues de Araújo ${ }^{I^{*}}$ Edna Ursulino Alves ${ }^{\mathrm{I}}$ Christiane Marques Rodrigues ${ }^{\mathrm{II}}$ \\ Antonio Augusto Marques Rodrigues ${ }^{\text {III }}$
}

RESUMO

As espécies frutíferas do gênero Eugenia têm grande potencial para recomposição ambiental, possibilitando não somente a recuperação da flora como também a atração da fauna. O presente trabalho teve como objetivo avaliar o efeito de diferentes tratamentos para remoção da polpa sobre a emergência e crescimento inicial de plântulas de Eugenia jambolana Lam. Os tratamentos utilizados foram: fricção com areia lavada $\left(T_{1}\right)$, cal virgem $\left(T_{2}\right)$, pó de madeira $\left(T_{3}\right)$, degustação humana $\left(T_{4}\right)$, fermentação por 24, 48, 72 e 96 horas $\left(T_{5}, T_{6}, T_{7} e\right.$ $T_{8}$, respectivamente) e a testemunha - fruto inteiro sem nenhum tratamento $\left(T_{q}\right)$. Após a remoção da polpa, as sementes foram lavadas em água corrente e submetidas à secagem em ambiente de laboratório durante 24 horas, sendo em seguida semeadas em bandejas contendo areia, utilizando-se quatro repetições de 25 sementes por tratamento. Na avaliação do efeito dos tratamentos, determinou-se o teor de água, porcentagem e índice de velocidade de emergência, comprimento e massa seca de plântulas. O teor de água das sementes reduziu nos tratamentos de fricção com cal e remoção humana, sendo mais elevado na testemunha, mas todos os tratamentos promovem elevados percentuais de emergência em relação à testemunha, sendo os melhores resultados de vigor obtidos nos tratamentos de remoção humana e fermentação por 24 e 96 horas.

Palavras-chave: Myrtaceae, frutífera, recalcitrante, vigor.

\section{ABSTRACT}

The fruit species of the genus Eugenia have great potential for environmental restoration, enabling not only the recovery of flora and fauna attraction. In the present research it was evaluated the effect of different treatments for removal of the pulp on the emergence and early growth of seedlings of Eugenia jambolana Lam. The treatments were rubbing with sand (T1), lime
(T2), wood dust (T3), human tasting (T4), fermented for 24, 48, 72 and 96 hours (T5, T6, T7 and T8, respectively) and the control - whole fruit without any treatment (T9). After removing the pulp the seeds were washed in water and subsequently dried in a lab environment for 24 hours, and then sown in trays containing sand, using four replicates of 25 seeds per treatment. In assessing the effect of treatments it was determined the water content, percentage and index of germination speed, length and seedling dry weight. The water content of seed treatments reduced friction with lime and removing human, being higher in the control, but all treatments promoted high rates of emergency in relation to the control and the best results obtained in vigor removal treatments and human fermented for 24 and 96 hours.

Key words: Myrtaceae, species fruit, recalcitrant, vigor.

\section{INTRODUÇÃO}

O gênero Eugenia destaca-se como um dos mais importantes da família Myrtaceae, com espécies que têm considerável valor comercial e nutritivo (SILVA, 2000), potencial para recomposição ambiental, possibilitando não somente a recuperação da flora, como também a atração da fauna (MALUF et al., 2003), sendo que representam uma das maiores famílias da flora brasileira, contudo a exploração ainda é muito pequena (LORENZI, 2002).

As sementes de algumas espécies são envolvidas por uma mucilagem de difícil remoção, a qual pode prejudicar a germinação e o crescimento

\footnotetext{
'Departamento de Fitotecnia e Ciências Ambientais (DFCA), Centro de Ciências Agrárias (CCA), Universidade Federal da Paraíba (UFPB), 58397-000, Areia, PB, Brasil. E-mail: lraraujo1@yahoo.com.br. *Autor para correspondência.

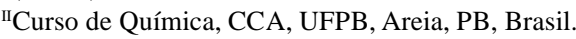

IIIPrograma de Pós-graduação em Agronomia, CCA, UFPB, Areia, PB, Brasil. 
de plântulas por favorecer o desenvolvimento de microrganismos ou conter substâncias inibidoras de germinação (CARMONA et al., 1994). Dessa forma, a mucilagem pode ser removida por fermentação natural, processos mecânicos ou químicos e, ainda, por métodos manuais, com a utilização de materiais abrasivos, tais como: areia, pó de madeira, cal virgem, fricção em peneira, entre outros (CARVALHO \& NAKAGAWA, 2010).

A escolha do método de remoção da mucilagem é feita em função das características do fruto, da maneira como se encontra aderida à semente, da presença de envelope mucilaginoso envolvendo a semente, entre outros (SILVA, 2000). Desses, o processo mais comum de eliminação da mucilagem em sementes de várias espécies é a fermentação, que, além de proporcionar a limpeza das sementes, pode ajudar no controle de doenças transmissíveis por elas (MANICA, 1981), sendo o tempo variável conforme a espécie e temperatura (SILVA, 2000).

Estudos realizados com Punica granatum L. indicaram maior vigor de plântulas originadas de sementes submetidas à fermentação por 72 horas (LOPES et al., 2001). Quando as sementes de Garcinia mangostana L. foram submetidas à fermentação por 48 horas, NASCIMENTO et al. (2001) obtiveram uma maior porcentagem de germinação. Resultados semelhantes foram obtidos por ALVES et al. (2009) quando verificaram os maiores índices de velocidade de emergência de plântulas de Talisia esculenta Radlk, oriundas de sementes postas para fermentar por 104 horas.

No entanto, a fermentação provocou redução na porcentagem de emergência de plântulas de Eugenia stipitata ssp. Sororia Mc Vaugh quando oriundas de sementes submetidas à fermentação por mais de 24 horas, enquanto a fricção em cal, serragem e peneira não afetaram a emergência das plântulas (GENTIL \& FERREIRA, 2000). Para sementes de Passiflora edulis f. flavicarpa Deg., MARTINS et al. (2006) indicaram a extração do arilo por meio de fricção sobre peneira de malha de aço por três minutos, imersão em cal virgem a $10 \%$ durante 10 minutos, fricção sobre peneira de malha de aço com areia grossa por três minutos e fermentação natural por seis dias, uma vez que promoveram uma germinação mais rápida.

Diante dessas considerações, no presente trabalho, teve-se como objetivo avaliar o efeito de diferentes tratamentos para remoção da polpa que envolve a semente sobre a emergência e crescimento inicial de plântulas de $\boldsymbol{E}$. jambolana.

\section{MATERIAL E MÉTODOS}

O presente trabalho foi realizado no Laboratório de Análise de Sementes do Departamento de Fitotecnia e Ciências Ambientais do Centro de Ciências Agrárias da Universidade Federal da Paraíba, em Areia-PB, utilizando-se sementes oriundas de frutos maduros de Eugenia jambolana, colhidos em árvores nativas no mesmo município.

As sementes de $\boldsymbol{E}$. jambolana foram submetidas aos seguintes tratamentos: fricção com areia lavada $\left(\mathrm{T}_{1}\right)$, cal virgem $\left(\mathrm{T}_{2}\right)$, pó de madeira $\left(\mathrm{T}_{3}\right)$, degustação humana $\left(\mathrm{T}_{4}\right)$ e fermentação por 24 , 48,72 e 96 horas $\left(\mathrm{T}_{5}, \mathrm{~T}_{6}, \mathrm{~T}_{7}\right.$ e $\mathrm{T}_{8}$, respectivamente) e testemunha - fruto inteiro sem nenhum tratamento $\left(\mathrm{T}_{9}\right)$. Nos tratamentos de fricção, os frutos foram misturados aos produtos citados anteriormente, colocados em bandejas plásticas e friccionados por uns dez minutos, enquanto na degustação humana a polpa dos frutos foi consumida até que as sementes ficassem limpas. Para os tratamentos com fermentação, os frutos foram colocados dentro de bandejas plásticas e, após o término de cada período, lavados em água corrente, friccionando-se uns aos outros sobre peneiras.

Após a remoção da polpa, nos diferentes tratamentos, as sementes foram lavadas em água corrente e submetidas à secagem à sombra, em condições de laboratório, durante 24 horas, sendo, em seguida, semeadas; na avaliação do efeito dos tratamentos, determinaram-se as variáveis descritas a seguir:

Teor de água - determinado pelo método padrão da estufa a $105 \pm 3^{\circ} \mathrm{C}$ durante 24 horas, conforme prescrições das Regras para Análise de Sementes (BRASIL, 2009). Foram utilizadas quatro repetições de 10 sementes por tratamento, sendo os resultados expressos em porcentagem.

Teste de emergência - utilizaram-se quatro repetições de 25 sementes, as quais foram semeadas em bandejas plásticas contendo como substrato areia lavada e esterilizada em autoclave, sendo a umidade mantida através de regas diárias com regador manual. As avaliações do número de plântulas emergidas foram realizadas diariamente, seguindose preferencialmente o mesmo horário, até o $21^{\circ}$ dia após a semeadura.

Índice de velocidade de emergência (IVE) - realizado juntamente com o teste de emergência, com contadas diárias das plântulas emergidas dos 10 aos 21 dias após a instalação do teste, sendo o índice determinado de acordo com a fórmula proposta por MAGUIRE (1962). 
Comprimento da parte aérea e da raiz - no final do teste de emergência, as plântulas normais de cada repetição foram medidas com o auxílio de uma régua graduada em centímetros, e os resultados expressos em cm plântula ${ }^{-1}$.

Massa seca da parte aérea e raízes - após as medições, as plântulas foram postas em sacos de papel do tipo Kraft e secas em estufa regulada a $65^{\circ} \mathrm{C}$ até atingir peso constante e, decorrido esse período, pesadas em balança com precisão de $0,001 \mathrm{~g}$, cujos resultados foram expressos em g plântula ${ }^{-1}$.

Delineamento experimental e análise estatística - o delineamento experimental utilizado foi inteiramente ao acaso com nove tratamentos, em quatro repetições, sendo os dados submetidos à análise de variância e as médias comparadas pelo teste de Scott-Knott a 5\% de probabilidade, utilizando-se o programa estatístico SISVAR.

\section{RESULTADOS E DISCUSSÃO}

O teor de água das sementes foi elevado, variando entre 40 e $72 \%$, independente do método de remoção utilizado. No entanto, o maior teor de água foi verificado nas sementes da testemunha $\left(\mathrm{T}_{9}\right)$, provavelmente devido à presença da mucilagem, que proporcionou uma maior retenção de água. Para as sementes dos tratamentos de fricção com cal virgem $\left(\mathrm{T}_{2}\right)$ e degustação humana $\left(\mathrm{T}_{4}\right)$, constataram-se os menores teores de água, indicando que estes foram eficientes na remoção da polpa e, com isso permitiram uma secagem mais eficiente (Tabela 1).

Em sementes de espécies brasileiras do gênero Eugenia, DELGADO \& BARBEDO
(2007) verificaram elevados teores de água após o beneficiamento, sendo considerado uma das principais causas da perda do poder germinativo e vigor das sementes (CARVALHO \& NAKAGAWA, 2010).

Todos os métodos utilizados para remoção da polpa proporcionaram elevados percentuais de emergência de plântulas de $\boldsymbol{E}$. jambolana, comprovando, assim, que a presença da mucilagem nas sementes (testemunha) inibiu a germinação, sendo necessária a utilização de métodos de remoção adequados para removê-la (Tabela 1), uma vez que a sua presença também pode proporcionar o desenvolvimento de patógenos e ainda conter substâncias reguladoras de crescimento, as quais contribuem para a desuniformidade na germinação (PEREIRA \& DIAS, 2000).

Em relação ao índice de velocidade de emergência (Tabela 1), os maiores valores foram obtidos com as plântulas oriundas das sementes submetidas aos tratamentos de degustação humana $\left(\mathrm{T}_{4}\right)$ e fermentação por 24 e 96 horas $\left(\mathrm{T}_{5}\right.$ e $\mathrm{T}_{8}$, respectivamente), verificando-se que os referidos tratamentos foram eficientes na remoção da polpa, eliminando, assim, algum provável inibidor da germinação.

Com relação ao comprimento da parte aérea, constatou-se interferência negativa apenas do tratamento de fermentação por 24 horas $\left(\mathrm{T}_{5}\right) \mathrm{e}$ das sementes da testemunha $\left(\mathrm{T}_{9}\right)$, uma vez que se obtiveram os menores valores (Tabela 2); nos demais tratamentos, verificaram-se os maiores comprimentos da parte aérea das plântulas. A interferência negativa de poucos tratamentos no comprimento da parte aérea

Tabela 1 - Teor de água das sementes, emergência e índice de velocidade de emergência de plântulas (IVE) de $\boldsymbol{E}$. jambolana em função de diferentes tratamentos para remoção da polpa.

\begin{tabular}{|c|c|c|c|}
\hline & Teor de água & Emergência & IVF \\
\hline $\mathrm{T}_{1}$ & $42,75 \mathrm{~b}$ & $98 \mathrm{a}$ & $7,43 \mathrm{~b}$ \\
\hline $\mathrm{T}_{2}$ & $40,75 \mathrm{~b}$ & $100 \mathrm{a}$ & $6,28 \mathrm{~b}$ \\
\hline $\mathrm{T}_{3}$ & $43,00 \mathrm{~b}$ & $99 \mathrm{a}$ & $6,78 \mathrm{~b}$ \\
\hline $\mathrm{T}_{4}$ & $40,00 \mathrm{~b}$ & $97 \mathrm{a}$ & $8,82 \mathrm{a}$ \\
\hline $\mathrm{T}_{5}$ & $43,25 \mathrm{~b}$ & $99 a$ & $10,36 \mathrm{a}$ \\
\hline $\mathrm{T}_{6}$ & $42,75 \mathrm{~b}$ & $90 a$ & $6,73 \mathrm{~b}$ \\
\hline $\mathrm{T}_{7}$ & $43,00 \mathrm{~b}$ & $98 \mathrm{a}$ & $6,26 \mathrm{~b}$ \\
\hline $\mathrm{T}_{8}$ & $45,25 \mathrm{~b}$ & $94 \mathrm{a}$ & $8,63 \mathrm{a}$ \\
\hline $\mathrm{T}_{9}$ & $72,00 \mathrm{a}$ & $18 \mathrm{~b}$ & $0,42 \mathrm{c}$ \\
\hline
\end{tabular}

Médias seguidas de mesma letra na coluna não diferem estatisticamente entre si, pelo teste de Scott-Knott a 5\% de probabilidade.

$\mathrm{T}_{1}$ - fricção com areia, $\mathrm{T}_{2}$ - cal virgem, $\mathrm{T}_{3}$ - pó de madeira - $\mathrm{T}_{4}$ - degustação humana, $\mathrm{T}_{5}, \mathrm{~T}_{6}, \mathrm{~T}_{7}$ e $\mathrm{T}_{8}$ - fermentação por $24,48,72$ e 96 horas, respectivamente, $\mathrm{T}_{9}$ - testemunha (fruto inteiro sem nenhum tratamento). 
Tabela 2 - Comprimento e massa seca de plântulas de $\boldsymbol{E}$. jambolana em função de diferentes tratamentos para remoção da polpa.

\begin{tabular}{|c|c|c|c|c|}
\hline \multirow{2}{*}{ Tratamentos } & & & \multicolumn{2}{|c|}{--Massa seca (g) } \\
\hline & Raiz & Parte aérea & Raízes & Parte aérea \\
\hline $\mathrm{T}_{1}$ & $8,34 \mathrm{~b}$ & $7,26 \mathrm{a}$ & $0,75 \mathrm{a}$ & $1,75 \mathrm{a}$ \\
\hline $\mathrm{T}_{2}$ & $8,83 \mathrm{~b}$ & $7,60 \mathrm{a}$ & $0,75 \mathrm{a}$ & $1,25 \mathrm{~b}$ \\
\hline $\mathrm{T}_{3}$ & $8,37 \mathrm{~b}$ & $7,22 \mathrm{a}$ & $1,00 \mathrm{a}$ & $1,00 \mathrm{~b}$ \\
\hline $\mathrm{T}_{4}$ & $10,1 \mathrm{a}$ & $8,23 \mathrm{a}$ & $1,00 \mathrm{a}$ & $2,00 \mathrm{a}$ \\
\hline $\mathrm{T}_{5}$ & $7,23 \mathrm{~b}$ & $5,73 \mathrm{~b}$ & $0,57 \mathrm{~b}$ & $1,00 \mathrm{~b}$ \\
\hline $\mathrm{T}_{6}$ & $8,44 \mathrm{~b}$ & $7,81 \mathrm{a}$ & $0,75 \mathrm{a}$ & $1,25 \mathrm{~b}$ \\
\hline $\mathrm{T}_{7}$ & $8,28 \mathrm{~b}$ & $7,05 \mathrm{a}$ & $0,75 \mathrm{a}$ & $1,25 \mathrm{~b}$ \\
\hline $\mathrm{T}_{8}$ & $9,00 \mathrm{~b}$ & $7,55 \mathrm{a}$ & $1,00 \mathrm{a}$ & $1,75 \mathrm{a}$ \\
\hline $\mathrm{T}_{9}$ & $6,81 \mathrm{~b}$ & $3,78 \mathrm{c}$ & $0,60 \mathrm{~b}$ & $0,60 \mathrm{c}$ \\
\hline
\end{tabular}

Médias seguidas de mesma letra na coluna não diferem estatisticamente entre si, pelo teste de Scott-Knott a 5\% de probabilidade.

$\mathrm{T}_{1}$ - fricção com areia, $\mathrm{T}_{2}$ - cal virgem, $\mathrm{T}_{3}$ - pó de madeira - $\mathrm{T}_{4}$ - degustação humana, $\mathrm{T}_{5}, \mathrm{~T}_{6}, \mathrm{~T}_{7}$ e $\mathrm{T}_{8}$ - fermentação por $24,48,72$ e 96 horas, respectivamente, $\mathrm{T}_{9}$ - testemunha (fruto inteiro sem nenhum tratamento).

provavelmente se deve ao fato de ela não ficar em contato com as substâncias presentes na polpa. De acordo com ALVES et al. (2009), a fermentação de sementes de Talisia esculenta por 86 horas proporcionou o maior comprimento de plântulas (26 e $49 \mathrm{~cm})$.

O tratamento de degustação humana $\left(\mathrm{T}_{4}\right)$ foi o único que proporcionou o maior comprimento de raiz primária $(10,1 \mathrm{~cm})$ das plântulas de $\boldsymbol{E}$. jambolana (Tabela 2), verificando-se que os demais (fricção com areia, cal e pó de madeira, bem como os diferentes períodos de fermentação) comprometeram o vigor das sementes. Provavelmente, o tratamento de degustação humana foi o único que removeu completamente a polpa, eliminando assim algum inibidor da germinação, uma vez que não houve interferência negativa no comprimento da raiz, que fica em contato direto com as substâncias presentes na polpa.

Em pesquisa realizada por CARDOSO et al. (2001), o comprimento da raiz primária de plântulas de Passiflora edulis Sims. f. lavicarpa Deneger foi influenciado pela fermentação, devido à velocidade de emergência das plântulas.

A massa seca da parte aérea das plântulas de $\boldsymbol{E}$. jambolana (Tabela 2) variou com os métodos avaliados, sendo que a remoção feita por fricção com areia $\left(\mathrm{T}_{1}\right)$, degustação humana $\left(\mathrm{T}_{4}\right)$ e fermentação por 96 horas $\left(\mathrm{T}_{8}\right)$ proporcionaram maior conteúdo de massa seca. Mais uma vez, subtende-se que nestes tratamentos houve uma maior eficiência na eliminação da polpa, aliado ao fato de a parte aérea não ficar em contato direto com algum inibidor presente no substrato.
Para a massa seca das raízes (Tabela 2), verificou-se que a maior parte dos tratamentos proporcionou aumento de peso, com exceção da testemunha $\left(\mathrm{T}_{5}\right)$ e do tratamento com fermentação por 24 horas $\left(\mathrm{T}_{6}\right)$. CAVARIANI et al. (1994) verificaram que o vigor das sementes de Coffea arábica L., determinado pelo conteúdo de massa seca das plântulas, não foi comprometido pelo método de remoção da mucilagem através da fermentação. Já CARDOSO et al. (2001) não observaram influência de diferentes períodos de fermentação das sementes sobre o conteúdo de massa seca das plântulas de Passiflora edulis Sims. f. flavicarpa Deneger. No entanto, ALVES et al. (2009) constataram maiores valores $(0,270 \mathrm{~g})$ de massa seca de plântulas de T. esculenta, quando as sementes permaneceram em fermentação por 105 horas.

A determinação da massa seca de plântulas é uma maneira de avaliar o seu crescimento, uma vez que se consegue determinar, com precisão, a transferência de reservas da semente para o eixo embrionário (NAKAGAWA, 1999), de forma que as amostras com maior massa seca são consideradas de maior vigor.

\section{CONCLUSÃO}

Para remoção da polpa dos frutos de Eugenia jambolana e melhor expressão da qualidade fisiológica das sementes, o tratamento mais eficiente é o de degustação humana.

Ciência Rural, v.45, n.1, jan, 2015. 


\section{REFERÊNCIAS}

ALVES, E.U.; et al. Germinação e vigor de sementes de Talisia esculenta (St. Hil) Radlk em função de diferentes períodos de fermentação. Semina: Ciências Agrárias, Londrina, v.30, n.4, p.761-770, 2009. <http://dx.doi.org/10.5433/16790359.2009v30n4p761>.Acessoem: 12 jul. 2012 doi:10.5433/16790359.2009v30n4p761.

BRASIL. Ministério da Agricultura, Pecuária e Abastecimento. Regras para análise de sementes. Brasília: Secretaria de Defesa Agropecuária, MAPA/ACS, 2009. 395p.

CANDIANI, G. et al. Seed germination and removal of Michelia champaca L. (Magnoliaceae) in eucalypt stands: the influence of the aril. Revista Árvore, Viçosa, v.28, n.3, p.327-332, 2004. <http://www.scielo.br/scielo.php?pid=S0100$67622004000300002 \&$ script $=$ sci_arttext $>$. Acesso em 03 jul. 2012. doi:10.1590/S0100-67622004000300002.

CARDOSO, G.D. et al. Desenvolvimento de mudas de maracujazeiro-amarelo obtidas de sementes extraídas por fermentação. Revista Brasileira de Fruticultura, Jaboticabal, v.23, n.3, p.639-642, 2001. <http://www.scielo.br/scielo.php?script=sci_ issuetoc $\&$ pid $=0100-294520010003 \& \operatorname{lng}=$ pt $\& n r m=$ iso $>$. Acesso em 25 jun. 2012. doi: 10.1590/S0100-29452001000300039.

CARMONA, R. et al. Extração química de sementes de gabiroba (Campomanesia adamantium Camb.). Revista Brasileira de Sementes, Brasília, v.16, n.1, p.31-33, 1994. <http://farmaciapp. blog spot.com.br/2006/12/extrao-qumica-de-sementes-degabiroba.html>. Acesso em 22 jul. 2012.

CARVALHO, N.M.; NAKAGAWA, J. Sementes: ciência, tecnologia e produção. 4.ed. Jaboticabal: FUNEP, 2000. 580p.

CAVARIANI, C. et al. Métodos de remoção da mucilagem e qualidade fisiológica de sementes de tomate (Lycopersicon esculentum, Mill.). Scientia Agricola, Piracicaba, v.50, n.3, p.43-46, 1994. <http://www.scielo.br/scielo.php?script=sci_ arttext\&pid=S0103-90161994000100007\&lng=pt\&nrm=iso\&tlng $=\mathrm{pt}>$. Acesso em 06 jun. 2012. doi: 10.1590/ http://www.scielo.br/ scielo.php?script=sci_arttext\&pid=S0103-90161994000100007.

DELGADO, L.F.; BARBEDO, C.J. Tolerância à dessecação de sementes de espécies brasileiras de Eugenia. Pesquisa Agropecuária Brasileira, Brasília, v.42, n.2, p.265-272, 2007. <http://www.scielo.br/scielo.php?script=sci_arttext\&pid=S0100204X2007000200016>. Acesso em 01 jun 2012. doi: 10.1590/ S0100-204X2007000200016.

GENTIL, D.F.O.; FERREIRA, S.A.N. Métodos de extração e limpeza de sementes de araçá-boi (Eugenia stipitata ssp. sororia). Acta Amazonica, Manaus, v.30, n.1, p.23-30, 2000. <https://www. inpa.gov.br/cpca/periodicos.html>. Acesso em 06 jun 2012.
LOPES, K.L. et al. Comportamento de sementes de romã (Punica granatum L.) submetidas à fermentação e secagem. Revista Brasileira de Fruticultura, Jaboticabal, v.23, n.2, p.369-372, 2001. <http://www.scielo.br/scielo.php?script=sci_arttext\&pid=S0100$29452001000200034 \& \operatorname{lng}=\mathrm{pt} \& \mathrm{nrm}=\mathrm{iso} \& \ln \mathrm{l}=\mathrm{pt}>$. Acesso em 25 jun. 2012. doi: 10.1590/S0100-29452001000200034.

LORENZI, H. Árvores brasileiras: manual de identificação e cultivo de plantas arbóreas do Brasil. 4.ed. Nova Odessa: Instituto Plantarum, 2002. V.1, 368p.

MAGUIRE, J.D. Speed of germination aid in selection and evaluation for seedling emergence and vigor. Crop Science, Madison, v.2, n.2, p.176-177, 1962.

MALUF, A.M. et al. Drying and storage of Eugenia involucrata DC. seeds. Scientia Agricola, Piracicaba, v.60, n.3, p.471475, 2003. <http://www.scielo.br/scielo.php?pid=S0103$90162003000300009 \&$ script $=$ sci_arttext $>$. Acesso em 01 ago 2012. doi: 10.1590/ S0103-90162003000300009.

MANICA, I. Fruticultura Tropical: 1. Maracujá. São Paulo: Ceres, 1981. 151p.

MARTINS, M.R. et al. Influência de diferentes métodos de remoção do arilo na germinação de sementes de maracujazeiroamarelo (Passiflora edulis Sims f. flavicarpa Deg.). Revista da Faculdade de Zootecnia, Veterinária e Agronomia, Uruguaiana, v.13, n.2, p.28-38, 2006. <http://revistaseletronicas.pucrs.br/ojs/ index.php/fzva/article/view/203>. Acesso em 13 jul 2012.

NAKAGAWA, J. Testes de vigor baseados no desempenho das plântulas. In: KRZYZANOWSKI, F.C. (Ed.). Vigor de sementes: conceitos e testes. Londrina: ABRATES, 1999. p.2-21.

NASCIMENTO, W.M.O. et al. Comportamento fisiológico de sementes de mangostão (Garcinia mangostana L.) submetidas a diferentes períodos de fermentação da polpa. Revista Brasileira de Fruticultura, Jaboticabal, v.23, n.3, p.735-737, 2001. <http:// www.scielo.br/scielo.php? script $=$ sci_arttext $\&$ pid $=S 0100-$ $29452001000300059 \& \operatorname{lng}=\mathrm{pt} \& \mathrm{nrm}=\mathrm{iso} \& \mathrm{t} \operatorname{lng}=\mathrm{pt}>$. Acesso em 25 jun. 2012. doi: 10.1590/S0100-29452001000300059.

PEREIRA, K.J.C.; DIAS, D.C.F.S. Germinação e vigor de sementes de maracujá-amarelo (Passiflora edulis Sims. F. flavicarpa Deg.) submetidas a diferentes métodos de remoção da mucilagem. Revista Brasileira de Sementes, Londrina, v.22, n.1, p.288-291, 2000. <http://www.scielo. $\mathrm{br} / \mathrm{scielo} . \mathrm{php}$ ? script $=$ sci_nlinks\&ref $=000108 \& \mathrm{pid}=\mathrm{S} 0101-$ $3122200900040001300017 \& \operatorname{lng}=$ en>. Acesso em 20 jun 2012.

SILVA, R.F. Extração de sementes de frutos carnosos. In: CARVALHO, N.M.; NAKAGAWA, J. (Eds.). Sementes: ciência, tecnologia e produção. 4.ed. Jaboticabal: FUNEP, 2000. p.458484. 